\title{
Racial/Ethnic Disparities in US Pediatric Growth Hormone Treatment
}

\author{
Adda Grimberg $^{\mathrm{a}-\mathrm{c}}$ Anders Lindberg ${ }^{d}$ Michael Wajnrajch ${ }^{\mathrm{e}, f}$ \\ Andrew J. Cucchiarag Cecilia Camacho-Hübner ${ }^{\mathrm{e}}$ \\ a Department of Pediatrics, Perelman School of Medicine, University of Pennsylvania, Philadelphia, PA, USA; \\ ${ }^{b}$ Leonard Davis Institute of Health Economics, University of Pennsylvania, Philadelphia, PA, USA; 'Division of

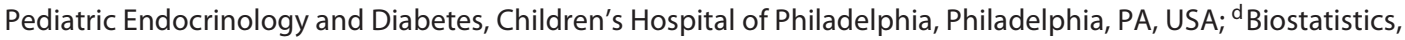

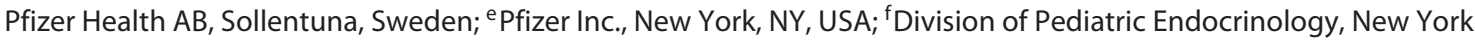 \\ University School of Medicine, New York, NY, USA; ${ }^{9}$ Center for Human Phenomics Science and Center for Clinical \\ Epidemiology and Biostatistics, Perelman School of Medicine, University of Pennsylvania, Philadelphia, PA, USA
}

\section{Keywords}

Growth hormone - Treatment - Disparities · Race · Pediatric primary care population

\begin{abstract}
Background/Aims: To compare racial/ethnic proportions of subjects receiving growth hormone $(\mathrm{GH})$ treatment to the expected proportions, and secondarily, to assess racial/ethnic differences in subject characteristics at GH treatment initiation. Methods: Race/ethnicity-based expected frequencies of height $<-2.25$ SD were determined by applying relative risks for short stature, calculated from a regional population of 189,280 pediatric primary care patients, to US census data, and compared to racial/ethnic proportions of US subjects enrolled in the Pfizer International Growth Study (KIGS) using the $X^{2}$ test. Characteristics of white and black subjects at GH treatment initiation were presented as medians and compared by the Wilcoxon rank sum test (significant $p<0.01)$. Results: White subjects exceeded the expected frequency $(63 \%)$ for all indications (83\%) and each separately, ranging from $73 \%$ for congenital GH deficiency (GHD) to
\end{abstract}

$85 \%$ for idiopathic short stature $(p<0.001)$. Compared to white subjects, black subjects treated for idiopathic GHD had greater height deficits relative both to the population ( -2.97 vs. $-2.56 \mathrm{SD})$ and to their mid-parental heights $(-2.47$ vs. $-1.89 \mathrm{SD}$ ), lower stimulated GH peak levels (4.9 vs. $6.0 \mathrm{ng} /$ $\mathrm{mL}$ ), and lower birth weights ( -0.86 vs. $-0.48 \mathrm{SD}$ ). Black subjects with congenital GHD had lower stimulated GH peaks ( $2.1 \mathrm{vs.} 3.2 \mathrm{ng} / \mathrm{mL}$ ) and started $\mathrm{GH}$ treatment at younger ages ( 2.9 vs. 4.8 years), while those with acquired GHD had lower birth weights ( -1.12 vs. -0.08 SD). Male predominance did not differ by race for any or all indications. Conclusion: Overrepresentation of white children among those receiving $\mathrm{GH}$ treatment in the US KIGS registry reflects racial/ethnic treatment biases, not just differences in growth rates.

(c) 2018 S. Karger AG, Basel

\section{Introduction}

White children are overrepresented relative to the general population from the earliest report of US growth hormone $(\mathrm{GH})$ registries [1] and among those seeking sub-

\section{KARGER}

(c) 2018 S. Karger AG, Basel

E-Mail karger@karger.com

www.karger.com/hrp
Adda Grimberg, MD

Division of Pediatric Endocrinology and Diabetes, Children's Hospital of Philadelphia 3401 Civic Center Boulevard, Suite 11NW30

Philadelphia, PA 19104 (USA)

E-Mail grimberg@email.chop.edu 
specialist care for short stature [2]. The National Health and Nutrition Examination Survey (NHANES) found that among US-born non-Hispanic children from birth cohorts of 1942-2002, black children were on average taller than white children in childhood and early adolescence [3, 4]. This was related to a faster tempo of growth starting at the age of 3 years, such that the average height differences between black and white children were $+1 \mathrm{~cm}$ for boys aged $2-10$ years, $+1.5 \mathrm{~cm}$ for boys aged $11-13$ years, +1.2 $\mathrm{cm}$ for girls aged $2-10$ years, and $+1.8 \mathrm{~cm}$ for girls aged 11-13 years. However, white teens caught up to black teens in height and ended up slightly taller, with average height differences between black and white teens aged 1419 years being $<-1 \mathrm{~cm}$ for boys and $-1.5 \mathrm{~cm}$ for girls. Associated with this growth pattern is an earlier onset of puberty by black children, when measured by both median age of entry and mean age at each Tanner stage [5].

A recent regional study of 189,280 pediatric primary care patients [6] confirmed lower odds of short stature among black than among white children and adolescents. Similar to earlier studies [7-10], higher odds of short stature among Asian and Hispanic children compared to white children were also shown. This regional study allowed quantification of the effect of race and ethnicity on the prevalence of short stature. Thus, we now sought to compare racial/ethnic proportions of subjects receiving GH treatment to the expected proportions based on US census and differences in growth rates, and secondarily, to assess racial/ethnic differences in other subject characteristics at initiation of $\mathrm{GH}$ treatment.

\section{Subjects and Methods}

\section{Determination of Expected Frequencies of Short Stature by}

\section{Race/Ethnicity}

The heterogeneous pediatric primary care population was drawn from the 28 practices in Pennsylvania, New Jersey, and Delaware affiliated with a tertiary pediatric hospital. The Children's Hospital of Philadelphia institutional review board approved this study and determined that the criteria under 45 CFR 46.116(d) were met for waiver of informed consent. The patient population had been described previously in detail [6]. Race/ethnicity-based odds ratios for height $<-2.25 \mathrm{SD}$ (i.e., short enough to meet FDAapproved criteria for $\mathrm{GH}$ treatment of idiopathic short stature [ISS]) were calculated from the 145,710 subjects with complete data by multivariable logistic regression modeling, controlling for gender, age, history of premature birth, BMI $z$-score, insurance type, primary care practice location (urban vs. nonurban), and number of well visits during the study period [6]. The odds ratios were converted to race/ethnicity-based relative risks using the formula for converting adjusted odds ratios from logistic regression into crude estimates of adjusted risk ratios suggested by Zhang and $\mathrm{Yu}$ [11]. Race/ethnicity-based expected frequencies of height
$<-2.25$ SD were then calculated by applying the risk ratios for short stature to racial/ethnic percentages from the 2011 US census [12].

\section{KIGS Data Collection}

The Pfizer International Growth Study (KIGS) database, established in 1987 and introduced in the US in 1996, is the world's largest post-marketing surveillance database of pediatric GH with data from 83,803 patients $(277,264$ patient-years) from 52 different countries [13]. The KIGS registry is an international database developed with the main objective of documenting long-term outcomes and safety of Genotropin (Pfizer Inc., USA) in children with short stature. Pediatric patients and their legal guardians were informed of and consented/assented to participate in the survey, which permits anonymous use of the data in compliance with privacy guidelines. Institutional review board approval was obtained per standards of the place and time. As of October 2012, KIGS was closed for further data collection and therefore transitioned to a static database.

This study focused on the US cohort of the KIGS database. Included in this analysis were data from all US subjects treated for ISS, idiopathic GH deficiency (GHD), congenital GHD, acquired GHD, or born small-for-gestational age (SGA). Diagnoses were made by individual KIGS investigators according to the KIGS Etiology Classification List. For the purpose of this analysis, diagnoses were reviewed and reclassified, if indicated (36 subjects with GHD were reclassified to ISS), to comply with the generally accepted threshold of peak GH levels on provocative testing of $\leq 10 \mathrm{ng} / \mathrm{dL}$ for all subjects with GHD and $>10 \mathrm{ng} / \mathrm{dL}$ for all subjects with ISS. Key variables of interest were race/ethnicity (as reported by the investigator on clinical research form and based on discussions with patient/parent[s]), gender, birth weight $z$-score, gender-adjusted mid-parental height $z$-score, maximal GH peak on provocative testing, IGF-I $z$-score, diagnosis, and at the time of $\mathrm{GH}$ therapy initiation, the key variables were age, height $z$-score, height $z$-score minus mid-parental height $z$-score, weight and BMI $z$-scores, and pubertal status.

\section{Statistical Analyses of the KIGS Data}

Standard descriptive statistics were tabulated for discrete (e.g., frequencies and percentages) and continuous (e.g., mean and standard deviation, median and interquartile range) subject characteristics. The racial/ethnic proportions of US subjects enrolled in the KIGS database, for all combined and individual indications, were compared by the $\chi^{2}$ test to race/ethnicity-based expected frequencies of height $<-2.25 \mathrm{SD}$. Characteristics of the white and black subjects at initiation of $\mathrm{GH}$ treatment were presented as medians (10th and 90th centiles) and compared by the Wilcoxon rank sum test (significant $p<0.01$ ). Gender ratios of each and combined indications were compared by the $\chi^{2}$ test. Statistical Analysis System version 9.2 (SAS Institute Inc., North Carolina, USA) was used for all statistical analyses.

\section{Results}

Of the 10,229 US subjects in the KIGS database, 8,173 $(80 \%)$ had race/ethnicity data recorded and were included in this study. White subjects exceeded the expected frequency of $63 \%$ (per US census data and the risk ratios for short stature; Table 1) for all indications (83\%) and each 
Fig. 1. White children and adolescents are overrepresented in the US KIGS database relative to the expected rate. Registry proportions compared to the expected rate by $\chi^{2}$ test. ISS, idiopathic short stature; IGHD, idiopathic growth hormone deficiency; SGA, born small-for-gestational age.

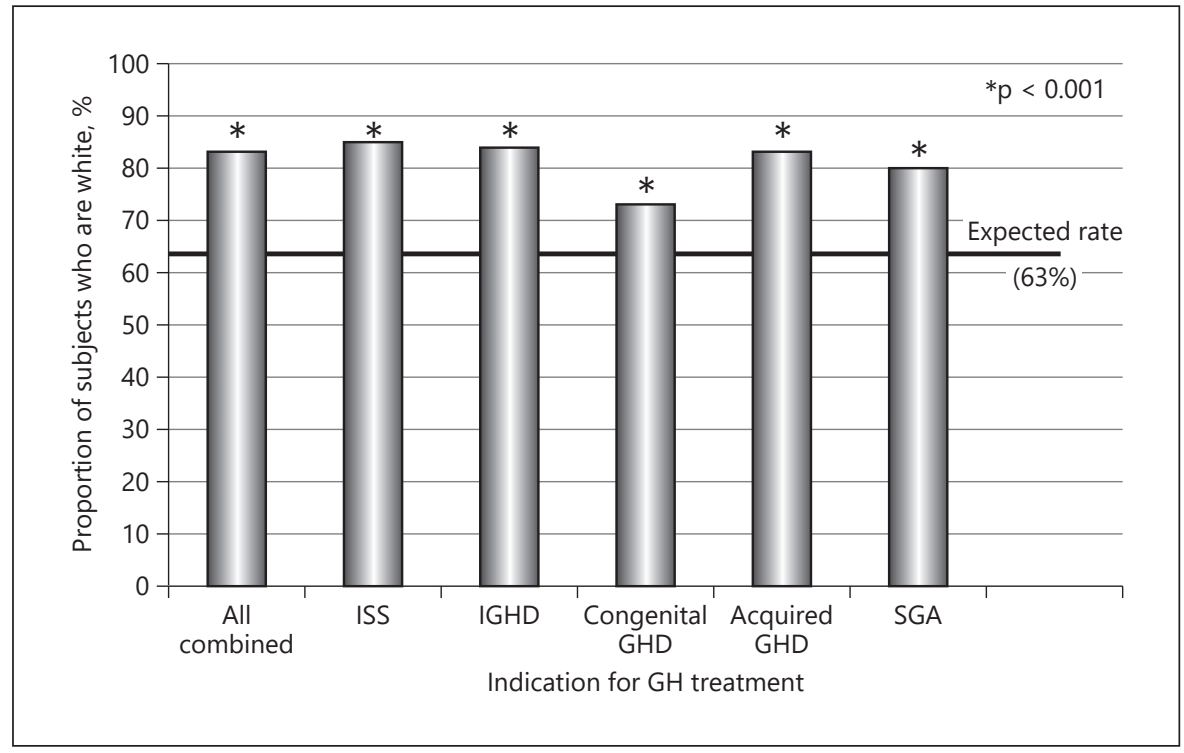

Table 1. Racial/ethnic proportions in US KIGS compared to the expected rates based on the 2011 US census and differences in growth patterns

\begin{tabular}{|c|c|c|c|c|c|c|c|c|c|}
\hline \multirow[t]{2}{*}{ Race/ethnicity } & \multicolumn{2}{|l|}{ Raw data } & \multirow{2}{*}{$\begin{array}{l}\text { Expected } \\
\text { frequency } \\
\text { (comparator), \% }\end{array}$} & \multicolumn{6}{|c|}{ US KIGS data, \% } \\
\hline & $\begin{array}{l}\text { relative risk for } \\
\mathrm{Ht}<-2.25 \mathrm{SD}\end{array}$ & $\begin{array}{l}\text { US census } \\
2011, \%\end{array}$ & & $\begin{array}{l}\text { all } \\
\text { combined }\end{array}$ & ISS & IGHD & $\begin{array}{l}\text { congenital } \\
\text { GHD }\end{array}$ & $\begin{array}{l}\text { acquired } \\
\text { GHD }\end{array}$ & SGA \\
\hline White & 1 & 63 & 63 & 83 & 85 & 84 & 73 & 83 & 80 \\
\hline Black & 0.66 & 13 & 9 & 4 & 3 & 3 & 11 & 4 & 6 \\
\hline Asian & 1.72 & 5 & 9 & 2 & 2 & 2 & 2 & 2 & 3 \\
\hline Hispanic & 1.86 & 17 & 32 & 7 & 7 & 7 & 8 & 8 & 8 \\
\hline Other & 0.85 & 2 & 2 & 3 & 3 & 3 & 4 & 3 & 3 \\
\hline$n$ & & & & 8,173 & 1,097 & 4,810 & 470 & 563 & 1,233 \\
\hline \multicolumn{4}{|c|}{$p$ value vs. comparator $\left(\chi^{2}\right)$} & $<0.001$ & $<0.001$ & $<0.001$ & $<0.001$ & $<0.001$ & $<0.001$ \\
\hline
\end{tabular}

Ht, height; ISS, idiopathic short stature; IGHD, idiopathic growth hormone deficiency; SGA, born small-for-gestational age.

separately, ranging from $73 \%$ for congenital GHD to $85 \%$ for ISS (every $p<0.001$; Table 1; Fig. 1). The congenital GHD group included 228 subjects with multiple pituitary hormone deficiencies and 242 with isolated GHD. Because short stature is more prevalent among Asian and Hispanic youth and adults in the US [6-10], their heights are more likely to be attributed by clinicians to familial short stature. Because treating familial short stature with $\mathrm{GH}$ is controversial, the remaining comparisons will focus on the black and white subjects in the US KIGS database.

Comparing the white and black subjects in the US KIGS (Table 2), black subjects in the idiopathic GHD group had greater height deficits relative to the popula- tion and their mid-parental heights, lower GH peaks on provocative testing, and lower birth weights. Black subjects with congenital GHD had lower GH peaks on testing and started GH treatment at younger ages, while those with acquired GHD had lower birth weights. Baseline characteristics did not differ significantly among those treated for ISS or SGA.

Male predominance did not differ by race/ethnicity (Table 3). Congenital GHD, the indication least dependent on a phenotype of short stature for diagnosis, had the least male predominance for both races. The combined effects of gender- and race/ethnicity-based disparities were pronounced for the ISS indication (Fig. 2). In 
Table 2. Baseline characteristics of black versus white subjects in the US KIGS by indication

\begin{tabular}{|c|c|c|c|c|c|c|c|}
\hline \multirow[t]{2}{*}{ Indication } & \multicolumn{3}{|c|}{ Black subjects } & \multicolumn{3}{|c|}{ White subjects } & \multirow[t]{2}{*}{$p$ value } \\
\hline & $n$ & median & $\begin{array}{l}\text { 10th to } 90 \text { th } \\
\text { percentiles }\end{array}$ & $n$ & median & $\begin{array}{l}10 \text { th to } 90 \text { th } \\
\text { percentiles }\end{array}$ & \\
\hline \multicolumn{8}{|l|}{ Idiopathic GHD } \\
\hline Height SDS Prader & 168 & -3.0 & -4.9 to -1.8 & 4,063 & -2.6 & -3.8 to -1.4 & 0.0001 \\
\hline Height - mid-parental height SDS & 142 & -2.5 & -4.9 to -0.5 & 3,806 & -1.9 & -3.6 to -0.3 & 0.0001 \\
\hline $\mathrm{GH}$ peak on stim. test, $\mathrm{ng} / \mathrm{mL}$ & 168 & 4.9 & 1.1 to 9.1 & 4,063 & 6.0 & 1.9 to 9.2 & 0.0014 \\
\hline Birth weight SDS & 135 & -0.9 & -2.6 to 1.1 & 3,393 & -0.5 & -2.0 to 0.7 & 0.0021 \\
\hline Age at GH start, years & 168 & 10.9 & 3.7 to 15.8 & 4,063 & 11.5 & 4.4 to 14.9 & 0.7069 \\
\hline \multicolumn{8}{|l|}{ Congenital GHD } \\
\hline Height SDS Prader & 54 & -3.0 & -5.8 to -0.4 & 345 & -2.6 & -4.9 to 0.0 & 0.2347 \\
\hline Height - mid-parental height SDS & 6 & -2.9 & -5.9 to -0.4 & 285 & -2.5 & -5.1 to 0.2 & 0.2493 \\
\hline $\mathrm{GH}$ peak on stim. test, $\mu \mathrm{g} / \mathrm{L}$ & 24 & 2.1 & 0.5 to 3.9 & 198 & 3.2 & 0.6 to 9.7 & 0.0050 \\
\hline Birth weight SDS & 44 & -0.5 & -2.4 to 0.9 & 288 & -0.2 & -1.6 to 1.3 & 0.0893 \\
\hline Age at $\mathrm{GH}$ start, years & 54 & 2.9 & -0.2 to 13.1 & 345 & 4.8 & 0.8 to 13.3 & 0.0037 \\
\hline \multicolumn{8}{|l|}{ Acquired GHD } \\
\hline Height SDS Prader & 24 & -2.4 & -3.7 to -1.2 & 469 & -2.0 & -3.6 to -0.3 & 0.2683 \\
\hline Height - mid-parental height SDS & 19 & -2.3 & -3.8 to 1.1 & 406 & -1.8 & -3.8 to -0.2 & 0.4173 \\
\hline $\mathrm{GH}$ peak on stim. test, $\mathrm{ng} / \mathrm{mL}$ & 16 & 2.0 & -0.5 to 6.1 & 334 & 2.4 & 0.4 to 9.0 & 0.6534 \\
\hline Birth weight SDS & 16 & -1.1 & -2.7 to 1.0 & 341 & -0.1 & -1.3 to 1.6 & 0.0058 \\
\hline Age at GH start, years & 24 & 11.8 & -8.3 to 17.3 & 469 & 11.5 & 7.0 to 15.8 & 0.3601 \\
\hline \multicolumn{8}{|l|}{ SGA } \\
\hline Height SDS Prader & 80 & -3.0 & -4.5 to -2.3 & 981 & -3.0 & -4.4 to -1.8 & 0.3609 \\
\hline Height - mid-parental height SDS & 72 & -2.1 & -4.6 to -0.2 & 868 & -2.2 & -4.2 to -0.6 & 0.4013 \\
\hline $\mathrm{GH}$ peak on stim. test, $\mathrm{ng} / \mathrm{mL}$ & 25 & 17.2 & 7.8 to 40.0 & 253 & 15.90 & 7.1 to 29.3 & 0.3697 \\
\hline Birth weight, SDS & 71 & -2.4 & -4.1 to 0.4 & 907 & -2.3 & -3.8 to -0.5 & 0.7012 \\
\hline Age at $\mathrm{GH}$ start, years & 80 & 8.3 & 3.0 to 13.1 & 981 & 8.1 & 3.1 to 13.3 & 0.9496 \\
\hline \multicolumn{8}{|l|}{ ISS } \\
\hline Height SDS Prader & 30 & -2.6 & -3.4 to -2.1 & 929 & -2.7 & -3.7 to -1.6 & 0.6604 \\
\hline Height - mid-parental height SDS & 26 & -1.8 & -3.0 to -0.5 & 876 & -1.8 & -3.3 to -0.3 & 0.7626 \\
\hline $\mathrm{GH}$ peak on stim. test, $\mu \mathrm{g} / \mathrm{L}$ & 30 & 14.2 & 10.4 to 23.2 & 929 & 14.0 & 10.7 to 24.0 & 0.7960 \\
\hline Birth weight SDS & 22 & -1.1 & -3.0 to 0.3 & 782 & -0.6 & -2.2 to 0.9 & 0.1102 \\
\hline Age at $\mathrm{GH}$ start, years & 30 & 11.7 & 8.0 to 14.6 & 929 & 11.8 & 6.5 to 14.8 & 0.8581 \\
\hline
\end{tabular}

Traits compared included sex, birth weight $z$-score, gender-adjusted mid-parental height $z$-score, maximal GH peak on provocative testing, IGF-I $z$-score, diagnosis, and at the time of GH therapy initiation: age, height $z$-score, height $z$-score minus mid-parental height $z$-score, weight and BMI $z$-scores, and pubertal status. Only those with significant differences $(p<0.01)$ are shown. Differences with $p<0.01$ are highlighted in bold. ISS, idiopathic short stature; GHD, growth hormone deficiency; SGA, born small-for-gestational age.

absolute numbers, with male predominance superimposed on white predominance, of the 1,097 subjects with ISS in the US KIGS, only 6 were black females.

\section{Discussion}

In summary, white subjects in the US cohort of the KIGS database exceeded the expected frequency for all indications and each separately, least for congenital GHD and most for ISS. The former indication is least related to short stature, while the latter involves treatment primarily for the psychosocial aspects of short stature. Comparing the black to white subjects in the US cohort of the KIGS, the lower GH peaks on provocative testing for both the idiopathic and congenital GHD groups, the greater height deficits relative to the population and their midparental heights for the idiopathic GHD group, and the younger age at initiation of $\mathrm{GH}$ treatment for the congenital GHD group all suggest that the black subjects were 


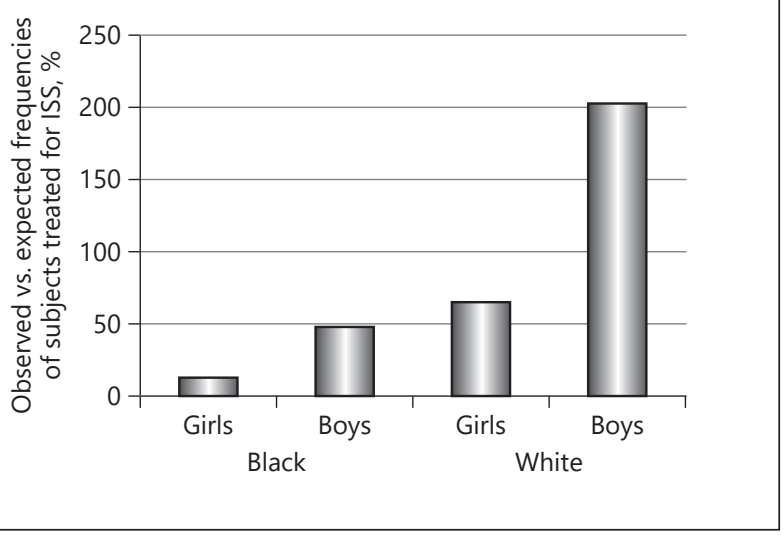

Fig. 2. White boys are overrepresented and black girls are particularly underrepresented among US KIGS subjects treated for idiopathic short stature (ISS). Ratios of frequencies, by race and gender, of US KIGS subjects treated for ISS to those expected based on population frequencies of height $<-2.25$ SD [6].

Table 3. Male predominance did not differ by race for any or all of the indications

\begin{tabular}{lrrrrrrl}
\hline Indication & \multicolumn{2}{c}{ White males } & & \multicolumn{2}{c}{ Black males } & \multirow{2}{*}{$p$ ( $\chi^{2}$ test $)$} \\
\cline { 2 - 3 } & $n$ & $\%$ & & $n$ & $\%$ & \\
\hline ISS & 704 & 76 & & 24 & 80 & 0.5948 \\
IGHD & 3,034 & 75 & & 132 & 79 & 0.2540 \\
Congenital GHD & 196 & 57 & & 28 & 52 & 0.4946 \\
Acquired GHD & 285 & 61 & & 16 & 67 & 0.5632 \\
SGA & 657 & 67 & & 62 & 78 & 0.0527 \\
\hline All combined & 4,876 & 72 & & 262 & 74 & 0.4732 \\
\hline
\end{tabular}

ISS, idiopathic short stature; IGHD, idiopathic growth hormone deficiency; SGA, born small-for-gestational age.

more severely affected at presentation. Taken altogether, these findings suggest racial/ethnic biases in US pediatric GH treatment. Statistically significant racial differences were not found in severity among KIGS subjects treated for ISS, which is the most subjective indication, but this may be due to the small numbers of black children treated for this indication. Male predominance did not differ by race.

In the absence of data on race/ethnicity-specific prevalence of the various growth disorders in the US population, one must turn to the relative proportions of the various racial/ethnic groups in the US population as comparators to the proportions seen in the KIGS database. However, the NHANES studies found race/ethnicity- based differences in growth rates among US children and adolescents [3-5]. Because all groups are evaluated clinically based on the same CDC growth charts, the faster growth rates reported in NHANES for black children may mask underlying growth problems in this group more so than for white children. Due to this phenomenon, to avoid overattributing racial differences in $\mathrm{GH}$ treatment to disparities, we corrected race/ethnicity proportions for relative risk of height $<-2.25 \mathrm{SD}$ before comparing them to race/ethnicity proportions in the KIGS. While such a correction may be more directly applicable to indications like ISS and idiopathic GHD than congenital GHD or SGA, not implementing this correction (i.e., comparing KIGS to the relative proportions of the various racial/ethnic groups in the US population) would not change any of our findings apart from making the apparent disparities that much bigger.

Where could such racial/ethnic biases come from? Race is often a surrogate for socioeconomic status and access to health care. This is illustrated by a comment in a parent focus group exploring parental concerns that impact their medical decision-making regarding a child's short stature: "There's so many other issues to be concerned about in the African-American community that I don't think that ... height and trying to address that through medicine would come at the top of the tier here ... on the other side, a family that may be more affluent, uh, particular a Caucasian family, maybe that would be something that they would consider" [14].

However, digging deeper, there may be other factors at play as well. In a survey of 1,820 parents of pediatric primary care patients, when asked "how short is too short for an adult" male or female, the median height provided by white parents was 2 in taller for both men and women than that provided by parents of all other racial and ethnic backgrounds [15]. Because short stature is more prevalent in the US among Asian and Hispanic Americans, their reported shorter acceptable height thresholds may reflect personal experience or the tendency to use oneself as a benchmark. However, this cannot explain the difference in height thresholds between black and white parents, whose adult heights tend to be more similar. Further, respondent traits found to be significant main effects in a parsimonious model of the reported acceptable height threshold were parents who were female, taller, white, wealthier, from nonurban primary care practices, and personally concerned about their own child's height [15]. The fact that race remained a significant explanatory variable in a model that included measures of socioeconomic status and access to health care (highest 
level of education completed, current employment status, total household annual income, insurance type, and primary care practice location) suggests that race is not merely a confounder; there are racial group differences in height-related perceptions that warrant further investigation.

Another possible factor is an interaction between race and religion. In both the qualitative parent groups and the quantitative survey portions of a mixed-methods study of height-related medical decision-making by parents of pediatric primary care patients, black parents were more likely than white parents to endorse a religious objection to pursuing medical height enhancement. They were more likely to express the belief that one's height is "the way God made you" and thus, should be accepted [14].

Gender-based disparities in US pediatric GH treatment have been reported previously $[6,16]$, as have gender-based disparities among patients seeking subspecialist care for short stature [17], diagnostic screening tests of the $\mathrm{GH}$ axis by primary care clinicians of their patients with growth faltering [18], and the likelihood of prescribing GH by pediatric endocrinologists [19]. Thus, it was interesting to see how the gender-based disparities interacted with racial differences in our current study. The previously reported 2:1 to 3:1 male:female ratios in US pediatric GH treatment [6] were seen in the US cohort of the KIGS database, similarly for both black and white subjects for each and combined indications. Thus, the social pressures for tallness on males in our society seem to cut across racial lines. Further, for black and white subjects alike, congenital GHD was the indication with the smallest gender gap. Congenital GHD is the indication least dependent on a phenotype of short stature for diagnosis; often those patients present with neonatal hypoglycemia, microphallus in boys, and/or midline or central nervous system defects.

The voluntary ascertainment of a registry study design introduced several possible limitations. Black patients may be less likely to obtain subspecialist care at a center participating in the KIGS study. Given the American history of racially based research maleficence [20], black patient-families may be less likely to consent to participate in medical research like the KIGS registry, or they may be less likely to report their racial/ethnic identity when asked. Other potential factors may include black patientfamilies not trusting doctors as much as they trust their religious leaders; too few same-race doctors, especially endocrinologists; and as seen in school-based or other nonreferred populations, not all families of short children are interested in seeking height-related medical care. All of these possibilities could lead to underrepresentation of black patients in the current study. Interestingly, the percentage of KIGS subjects with missing race/ethnicity data was greater in the US cohort (20\%) than the rest of the world (5\%). However, racial disparities were also seen in US studies of subspecialist care that were not dependent on voluntary ascertainment. In a study of patients with growth faltering from 4 urban pediatric primary care practices, black children were less likely to see a subspecialist than non-Hispanic white children, and the racial disparity was greater for endocrinology than gastroenterology appointments [18]. Likewise, white children were overrepresented (91\%) relative to the local general population in a study of parents of children seeking subspecialist care for short stature in a mid-sized, ethnically diverse US city [2]. Thus, these nonvoluntary ascertainmentbased studies support the notion of racial disparities in subspecialist referrals for short stature, which would then lead to racial disparities in $\mathrm{GH}$ treatment (GH is primarily prescribed by endocrinologists), as found in our current study. However, the $20 \%$ of US KIGS registry subjects with missing race/ethnicity data could not be analyzed and this could also have contributed to the study findings.

In conclusion, overrepresentation of white children among those receiving $\mathrm{GH}$ treatment and enrolled in the US KIGS registry suggests racial/ethnic treatment biases and not just differences in growth rates. Growth is a vital sign of child health and should receive equal importance for all children and adolescents [21]. Thus, more worrisome than GH treatment itself is the possibility that social biases can lead to missed diagnosis of underlying disease in short girls and children of racial/ethnic minorities, while promoting overzealous treatment of short, primarily white boys with an expensive medication.

\section{Acknowledgment}

The authors express their thanks to all American investigators and patient-families involved in providing data.

\section{Disclosure Statement}

A.G. is a member of the Steering Committee for the Pfizer International Growth Study (KIGS) database and received consultancy fees from Pfizer. M.W., C.C.-H. are and A.L. was full-time employees of Pfizer. A.J.C. has no conflict of interest to declare. No authors were paid for writing the manuscript. 


\section{Funding Sources}

This study was supported by Pfizer, Inc. The study used to determine relative risks of short stature was supported by an investigator-initiated grant from the Genentech Center for Clinical Research in Endocrinology (A.G.) and grants 1R01 HD57037 from the Eunice Kennedy Shriver National Institute of Child Health and Human Development (NICHD) (A.G.) and UL1TR000003 from the National Center for Advancing Translational Sciences (NCATS) (A.J.C.) of the National Institutes of Health (NIH). A.G. was supported by a Pediatric Academic Enrichment Fund Award from the Children's Hospital of Philadelphia.

\section{References}

1 August GP, Lippe BM, Blethen SL, Rosenfeld RG, Seelig SA, Johanson AJ, et al. Growth hormone treatment in the United States: demographic and diagnostic features of 2,331 children. J Pediatr. 1990 Jun;116(6):899-903.

2 Finkelstein BS, Singh J, Silvers JB, Marrero U, Neuhauser D, Cuttler L. Patient attitudes and preferences regarding treatment: GH therapy for childhood short stature. Horm Res. 1999; 51 Suppl 1:67-72.

3 Komlos J, Breitfelder A. Height of US-born non-Hispanic children and adolescents ages 2-19, born 1942-2002 in the NHANES samples. Am J Hum Biol. 2008 Jan-Feb;20(1): 66-71.

4 Komlos J, Breitfelder A. Differences in the physical growth of US-born black and white children and adolescents ages 2-19, born 1942-2002. Ann Hum Biol. 2008 Jan-Feb; 35(1):11-21.

5 Sun SS, Schubert CM, Chumlea WC, Roche AF, Kulin HE, Lee PA, et al. National estimates of the timing of sexual maturation and racial differences among US children. Pediatrics. 2002 Nov; 110(5):911-9.

6 Grimberg A, Huerta-Saenz L, Grundmeier R, Ramos MJ, Pati S, Cucchiara AJ, et al. Gender bias in U.S. pediatric growth hormone treatment. Sci Rep. 2015 Jun;5(1):11099.
7 Hyslop AE, Deinard AS, Dahlberg-Luby E, Himes JH. Growth patterns of first-generation Southeast Asian Americans from birth to 5 years of age. J Am Board Fam Pract. 1996 Sep-Oct;9(5):328-35.

8 Gjerdingen DK, Ireland M, Chaloner KM. Growth of Hmong children. Arch Pediatr Adolesc Med. 1996 Dec;150(12):1295-8.

9 Winham DM. Growth status among low-income Mexican and Mexican-American elementary school children. Am J Hum Biol. 2012 Sep-Oct;24(5):690-5.

10 Martorell R, Mendoza FS, Castillo RO. Genetic and environmental determinants of growth in Mexican-Americans. Pediatrics. 1989 Nov; 84(5):864-71.

11 Zhang J, Yu KF. What's the relative risk? A method of correcting the odds ratio in cohort studies of common outcomes. JAMA. 1998 Nov;280(19):1690-1.

12 US Census Bureau. State and County QuickFacts (cited 2012 Oct). Available from: http:// quickfacts.census.gov/qfd/states/42000.html.

13 Wilton P. KIGS: structure and organization. In: Ranke MB, Price DA, Reiter EO, editors. Growth hormone therapy in pediatrics - 20 years of KIGS. Basel: Karger; 2007. p. 1-5.

14 Grimberg A, Cousounis P, Cucchiara AJ, Lipman TH, Ginsburg KR. Parental concerns influencing decisions to seek medical care for a child's short stature. Horm Res Paediatr. 2015;84(5):338-48.
15 Cousounis PA, Lipman TH, Ginsburg K, Cucchiara AJ, Grimberg A. How short is too short according to parents of primary care patients. Endocr Pract. 2014 Nov;20(11): 1113-21.

16 Grimberg A, Stewart E, Wajnrajch MP. Gender of pediatric recombinant human growth hormone recipients in the United States and globally. J Clin Endocrinol Metab. 2008 Jun; 93(6):2050-6

17 Grimberg A, Kutikov JK, Cucchiara AJ. Sex differences in patients referred for evaluation of poor growth. J Pediatr. 2005 Feb;146(2): 212-6.

18 Grimberg A, Feemster KA, Pati S, Ramos M, Grundmeier R, Cucchiara AJ, et al. Medically underserved girls receive less evaluation for short stature. Pediatrics. 2011 Apr;127(4): 696-702.

19 Cuttler L, Silvers JB, Singh J, Marrero U, Finkelstein B, Tannin G, et al. Short stature and growth hormone therapy. A national study of physician recommendation patterns. JAMA. 1996 Aug;276(7):531-7.

20 Brandt AM. Racism and research: the case of the Tuskegee Syphilis Study. Hastings Cent Rep. 1978 Dec;8(6):21-9.

21 Grimberg A, Lifshitz F. Worrisome growth. In: Lifshitz F, editor. Pediatric endocrinology. 5th ed. New York: Informa Healthcare USA, Inc.; 2007. vol. 2, p. 1-50. 